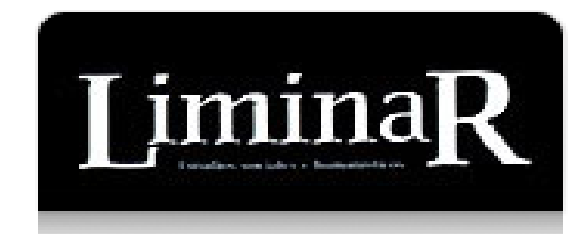

LiminaR. Estudios Sociales y Humanísticos ISSN: $1665-8027$

liminar.cesmeca@unicach.mx

Centro de Estudios Superiores de México y Centro América

México

Hernández-López, Rafael Alonso

De cómo la identidad étnica se vive en un contexto de migración: la presencia de migrantes chiapanecos en Los Altos de Jalisco

LiminaR. Estudios Sociales y Humanísticos, vol. XI, núm. 1, enero-junio, 2013, pp. 73-87

Centro de Estudios Superiores de México y Centro América

San Cristóbal de las Casas, México

Disponible en: http://www.redalyc.org/articulo.oa?id=74527869005

- Cómo citar el artículo

- Número completo

- Más información del artículo

- Página de la revista en redalyc.org

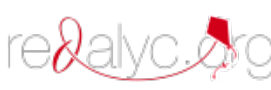

Sistema de Información Científica

Red de Revistas Científicas de América Latina, el Caribe, España y Portugal Proyecto académico sin fines de lucro, desarrollado bajo la iniciativa de acceso abierto 


\title{
DE CÓMO LA IDENTIDAD ÉTNICA SE VIVE EN UN CONTEXTO DE MIGRACIÓN: LA PRESENCIA DE MigRANTES CHIAPANECos en Los Altos de JaLisco
}

\author{
How Ethnic Identity is Experienced in the Context of Migration: \\ the Presence of Chiapas Migrants in Highland Jalisco \\ Rafael Alonso Hernández-López
}

Resumen: El presente escrito tiene la finalidad de poner de manifiesto cómo se ha conformado la identidadétnica en un municipio de Jalisco con la presencia de migrantes procedentes de Chiapas para trabajar en la agroindustria del tequila. Para ello, mediante análisis documental, discursivo y etnográfico, se rastrean momentos que, a juicio del autor, terminan por poner de manifiesto un "proceso de destilación étnica", metáfora que sirve para explicitar los procesos y dinámicas surgidas de las relaciones étnicas entre dos grupos supuestamente diferenciados cultural y racialmente: los indígenas migrantes y los alteños.

Palabras clave: identidad étnica, relaciones étnicas, migración, jornaleros, desigualdad, racismo.

Abstract: The present paper aims to show how the ethnic identity in a municipality of Jalisco, Mexico, has been built with the presence of migrants from Chiapas for working in the tequila industry. For such purpose, particular events have been traced, which for the author eventually reveal an "ethnic distillation process", metaphor used to explain the processes and dynamics that arise from the relations between two supposed culturally and racially distinct ethnic groups: indigenous migrants and native people from the High Lands Region.

Keywords: ethnic identity, ethnic relations, migration, laborers, inequality, racism.

Rafael Alonso Hernández López, candidato a doctor en Ciencias Sociales del Ciesas-Occidente. Temas de especialización: migración interna, racismo, etnicidad. Correo electrónico: loncho_hdz@hotmail.com, lonchohdz@gmail.com.
Enviado a dictamen: 29 de marzo de 2012

Aprobación: 07 de agosto de 2012

Revisiones: 1 


\section{Introducción}

$\amalg$ "proceso de destilación étnica" del que da cuenta este escrito surge como metáfora del proceso de destilación ${ }^{1}$ empleado en el mundo de la producción tequilera, el cual consiste, dicho someramente, en la separación y purificación de líquidos. Hablando exclusivamente de las identidades, al referirme a la destilación intento, por un lado, enmarcar el contexto social en el que se suscita la presente reflexión - el de las migraciones de jornaleros indígenas procedentes del sur del país, prioritariamente de Chiapas, para laborar en la agroindustria del tequila en Los Altos de Jalisco-y, por otro lado, poner énfasis en las relaciones étnicas que se generan en dicho espacio.

Pretendo referirme al hecho de que, frente a la presencia del "otro" y las subsecuentes relaciones sociales, la identidad de los alteños tiende a separarse, definirse y, en cierto punto, purificarse, recurriendo a marcadores y fronteras étnicas (Barth, 1976) y sociales construidas históricamente y actualizadas a través de una vivencia íntima (Epstein, 1978), la cual tiene su contraparte en prácticas que constatan que la diferencia tiende a ser un argumento de la desigualdad.

En la primera parte del trabajo se exponen algunos argumentos y rasgos históricos que dan cuenta de la conformación de la identidad étnica alteña, mientras que en un segundo momento se expone cómo esa identidad sale a relucir y se actualiza ante la llegada de los jornaleros indígenas marcando una diferencia étnica, cultural, que genera, tal como se esboza en las conclusiones, latentes expresiones y actitudes de desigualdad, que posibilitan a su vez la redefinición y distinción de un grupo confrontado, no por la salida de sus gentes a otros estados o al extranjero - por ejemplo, Estados Unidos-, sino por la llegada de otro que es concebido como inferior -indígenas de Chiapas-.

\section{Relaciones interétnicas en Los Altos de Jalisco²}

En el corazón de la república mexicana se encuentra una región habitada por gente que se aferra a los valores españoles (Taylor, 1989). Así da comienzo la obra en la que se exponen los resultados del trabajo de campo del antropólogo norteamericano Paul s. Taylor (1989) durante los años 1931-1932 en la población jalisciense de Arandas.

Ya hace casi 80 años, en la primera publicación de A Spanish-Mexican Peasant Community. Arandas in Jalisco, México (1933), ${ }^{3}$ Taylor aseguraba que la relativa soledad que se vivía en esa comunidad había permitido en gran medida la conservación de la herencia española. Hoy, varias décadas después y gracias a diferentes procesos económicos, políticos, sociales y culturales, y específicamente a la globalización, podemos servirnos del argumento opuesto para comprender los procesos y dinámicas sociales del mismo pueblo alteño. Es decir, ya no se trata de una comunidad aislada, encubierta, sino de una completamente abierta a todo tipo de circunstancias, dinámicas e ideologías. La globalización, entendida como un fenómeno social, económico, político, cultural y tecnológico, ha hecho más evidente y fluida la interconexión de esos fenómenos en grados y niveles nunca vistos, logrando una compresión del tiempo y del espacio, un sistema de comunicaciones en tiempo real, un despliegue tecnológico que ha acortado las distancias geográficas y un capital financiero situado estratégicamente en múltiples centros de poder.

Ante tales circunstancias, Arandas no ha sido una excepción y ha pasado a formar parte de los diversos procesos antes mencionados, siendo uno de los principales la producción tequilera regional y nacional. Esta situación ha posibilitado y hecho más evidente la relación de su gente con personas provenientes de otras áreas geográficas del país.

Si bien Taylor no se centra exclusivamente en el análisis identitario, su descripción nos da la pauta para entender parte de lo que a continuación se 
menciona como identidad alteña. En su definición del alteño, ${ }^{4}$ y más propiamente del arandense, Taylor traía a colación, primeramente, el hermetismo que primaba en la región en diversos ámbitos, siendo una muestra los matrimonios entre ellos, de tal suerte que se habían absorbido los elementos raciales de menor importancia y casi no había ocurrido la mezcla con los indígenas de las regiones vecinas. Nos dice además que, en esa época, conservaban algunos arcaísmos de la lengua que han desaparecido entre gente menos aislada. Destacaba también una especie de agrarismo natural que contrarresta con el sistema de hacienda que desempeñaba un papel menor en la región, puesto que una alta proporción de la población ha tenido acceso a la tierra de cultivo. De la vivencia cotidiana de Taylor entre los arandenses y su posterior descripción de los mismos, podemos rastrear, de entrada, varios elementos que permiten identificar características identitarias de los arandenses, destacando en primer lugar el reconocimiento de la honestidad y franqueza de los oriundos de la región (Taylor, 1989).

Complementariamente a la descripción de Taylor encontramos otros trabajos que también dan cuenta, mediante el recurso a los antecedentes históricos del municipio, de datos que nos sirven para seguir contextualizando y comprendiendo la configuración del imaginario identitario de los alteños. Resalta lo ya enunciado por historiadores con respecto a la región: que el área del actual Arandas fue evidentemente ocupada por indígenas, pacificada y cedida a hacendados españoles a finales del siglo XVI (Taylor, 1898). De esta suerte, Los Altos de Jalisco se configuraron como una zona de frontera entre Mesoamérica y Aridoamérica en la época precolombina, poblada por cazadores recolectores chichimecas de las etnias pame, guamar, guachichil, zacateca, caxcán, tecuexe y coca. Algunas de estas etnias practicaban la agricultura incipiente por temporadas (Fábregas, 1986). Después de la guerra del Mixtón de 1542, en la que las etnias chichimecas sostuvieron una lucha para frenar la ocupación y expulsar a los conquistadores españoles, los chichimecas fueron dispersados o, en su defecto, exterminados. Ahora bien, a fin de evitar nuevos enfrentamientos, los colonizadores trasladaron campesinos de diferentes partes de Castilla a poblar Los Altos de Jalisco.

El Estado español cedió la tierra en propiedad a estos grupos familiares, estrategia que garantizaba la ocupación permanente del territorio y, por consiguiente, el establecimiento de una frontera agrícola y ganadera que, además de proveer granos y carne a las zonas mineras, significaba una eficaz protección de las rutas comerciales (Fábregas, 2002). Esta última parte de la narrativa es la que primordialmente acentúan los habitantes de la región. Aun cuando se tienen datos de la conformación del municipio desde finales del siglo XVI, los primeros indicios de población serán de la segunda mitad del siglo XVIII (1760).

Entre los siglos XVI y XIX la principal actividad económica de estas sociedades fue la cría de ganado, con lo cual ya en el siglo XIX el rancho se había consolidado como unidad de vida campesina en Los Altos. Para entonces sostenía un elaborado conjunto de valores, hábitos y prácticas que permiten hablar de una cultura ranchera distintiva de la región y fuente de identidad de lo alteño (Gilabert, 2004). Esta trama ideológica de "lo ranchero" era nutrida por peculiares redes simbólicas y unos arreglos políticos que permitieron a un reducido grupo de familias mantener una continuidad secular en el ejercicio del poder, dominando las estructuras locales de organización política durante varias generaciones. El papel de la Iglesia católica fue desde entonces un componente de legitimidad aliado con las oligarquías o incluso formaba parte de ellas (Gilabert, 2004) hasta la guerra de Independencia, cuando fue separada del poder gubernamental.

La Iglesia sostuvo una confrontación con la nueva estructura liberal del Estado mexicano que le llevó a aliarse con los gobiernos conservadores para ser después una de las principales protagonistas de la 
contrarrevolución mexicana en la guerra cristera (López, 1999), uno de cuyos escenarios más importantes fueron Los Altos de Jalisco.

A propósito de la gente de Arandas, Taylor nos dice que, efectivamente, ésta se considera y define como un grupo español, fundamentalmente por sus rasgos fenotípicos: tez blanca, frecuentemente ojos azules y, en general, rasgos físicos más españoles que indígenas, altos, de complexión fuerte. Taylor también reconoce la existencia de una minoría de indígenas y mestizos, e incluso algunas veces se percibe una combinación de pigmentación u otro rasgo indígena y ojos azules. Y aún más, reconoce la ocasional presencia de características negroides (Taylor, 1989), acotando que los elementos raciales subordinados tendieron a desaparecer, resultando así más evidente el predominio de la sangre hispana.

Llama la atención una mención que Taylor hace al respecto. Se trata del elemento indio de la población, generalmente muy diluido, el cual, según él, se reconoce generalmente y es completamente evidente en todas las partes del municipio, especialmente en el pueblo de Arandas y en los ranchos más grandes. Entre los pequeños ranchos de Los Altos, la sangre española predominaba generalmente. Quizá una explicación de tal fenómeno de contrastación es que en el poblado mayor, en este caso Arandas, era donde había más bienes y servicios, lo que visibilizaba en un mismo núcleo las características de los diferentes miembros de la población, mientras en los ranchos de menor tamaño la dispersión contribuía quizá a invisibilizar o hacer menos latente la presencia de fenotipos contrastantes.

Interesante es que el análisis no se queda sólo en la demostración de los componentes raciales de la región, sino que además realiza una reflexión sobre las actitudes raciales de la gente de Arandas, pues forman parte del discurso sobre la identidad de los alteños. Dichas actitudes eran uniformes y reflejaban un fuerte orgullo por los ancestros españoles, un sentimiento de superioridad y una oposición a mezclarse con mestizos e indígenas (Taylor, 1989).

Debido a su interés por la cuestión migratoria, Taylor no deja pasar la oportunidad de relacionar dichas actitudes, previamente reconocidas como locales y europeas, con una influencia norteamericana, destacando, por ejemplo, la valorización de la piel blanca como un atributo personal, situación que pone de manifiesto la existencia de personas con una fuerte conciencia racial y un sentimiento de superioridad u, ocasionalmente, de inferioridad. Aun cuando existían tales prejuicios raciales, era evidente también una actitud de tolerancia hacia los que no gozaban de ser portadores de la herencia española (Taylor, 1989).

A mediados del siglo XX, la unidad productiva y base de la vida rural seguía siendo el rancho; la propiedad privada de la tierra, sustentada en los lazos familiares, evolucionó hacia un patrón de extensiones medianas y pequeñas, más que de grandes propiedades, en obediencia a la forma predominante de transmisión por herencia que distribuye a partes iguales entre los herederos, sin distinción de mujeres u hombres, lo cual favoreció la celebración de matrimonios entre parientes y la conformación de grupos de familias muy poderosas, con pretensiones latifundistas, y cuyos lazos favorecían el acceso a capitales económicos y políticos (Gilabert, 2004). En Los Altos de Jalisco, la familia nuclear inscrita en lazos extensos de parentesco continúa siendo el núcleo organizador de la vida social en un contexto donde la demografía es aún densa (Fábregas, 2001).

La pequeña propiedad tiende a corresponderse con las unidades de producción de las unidades domésticas campesinas y granjeras que se dedican predominantemente a la producción de autoconsumo y, cuando esto no se logra de modo constante, algunos de sus miembros recurren a la estrategia adaptativa de la venta de mercancía-trabajo, lo que explica la expulsión de la fuerza de trabajo en la región alteña (López, 1999). La expulsión constante de braceros, fenómeno de la Revolución que tuvo su despunte durante la guerra 
cristera, se mantuvo hasta la década de 1980 y obligó a un nuevo cambio tecnológico por la ausencia de fuerza de trabajo, pasando de manejos agrícolas extensivos a intensivos (López, 1999).

Taylor da cuenta de dicho fenómeno migratorio; incluso se aventura a indicar que es en 1905 cuando se registra el primer caso de migración internacional a los Estados Unidos, destacando como explicaciones: la presión poblacional sobre la tierra continuamente subdividida, el desorden político - guerra de Independencia, Revolución-y las luchas religiosas - guerra cristera- Para 1930, según los registros de Taylor, la migración ya había contribuido a configurar varias de las prácticas y estilos de vida de los arandenses, tales como la disminución de la tasa de natalidad o el incremento de la edad matrimonial, de tal suerte que Taylor reconoce dicha población como una sociedad con costumbres cambiantes en una región cada vez menos aislada y cuya organización social se hace gradualmente más compleja.

Con estas circunstancias de fondo y abonando tal complejidad, destaca la injerencia actual de diversas empresas transnacionales, así como de demandas de abasto muy específicas que han incidido para definir la lógica de producción especializada de Los Altos delimitándola en cuatro vetas: la ganadería de leche, la avicultura, la porcicultura y el tequila (Gilabert, 2004). Una región de "tierras flacas" (Yáñez, 1978) que ancestralmente ha luchado contra la escasez de agua, constreñida a lo que ofrecen las erráticas lluvias de temporal, ahora debe afrontar también los estragos de la sobreexplotación de sus recursos naturales y humanos (Gilabert, 2004).

En los últimos años, el uso del suelo ha cambiado radicalmente, las plantaciones de agave han convertido la tierra en un tapete azul que pone de manifiesto las grandes extensiones de tierra sembradas con dicha planta. Obviamente, esto se ha traducido en la creciente instalación de fábricas productoras de tequila, así como en la producción de grandes volúmenes de tal bebida.
En las localidades de Arandas y Atotonilco El Alto se encuentra plantada la mayor cantidad de agave de la región.

Entre los factores que agilizaron el proceso de producción tequilera a gran escala se encuentran, por citar algunos, los acuerdos comerciales que crearon condiciones favorables para la exportación del tequila y la participación de empresas transnacionales con inversiones que han permitido la modernización del sector tequilero. Además, la bebida y la marca tequila pasaron a ser un referente de la identidad nacional, lo cual impactó favorablemente en el consumo nacional y de mexicanos radicados en el extranjero (Hernández, 2005). Dicho contexto ayuda a explicar y comprender mejor los fenómenos que acaecen actualmente en el espacio geográfico citado, dado que se ha venido constituyendo como un importante mercado laboral para los jornaleros migrantes provenientes de Chiapas.

\section{El contacto cultural más reciente}

Debido en parte a la importante migración internacional de la gente de Arandas hacia los Estados Unidos, Taylor reconocía que se había dado un nuevo contacto entre culturas diferentes; de hecho, nos dice, en su época era el último de una serie de contactos culturales que empezaron con la conquista española o quizá antes (Taylor, 1989). Sin embargo, como se dijo en el apartado anterior, gracias a las nuevas dinámicas sociales, económicas, políticas y culturales, Arandas ha tenido un contacto cultural más reciente, no sólo por la migración de arandenses o alteños que van a otras entidades del país o incluso a otros países, sino por la llegada de jornaleros migrantes indígenas ${ }^{5}$ a esta zona del país, migrantes cuya condición étnica da una peculiaridad a la problemática en cuestión.

Sucede ahora que los contenidos fundantes de la identidad alteña —el origen europeo, particularmente español, el acendrado catolicismo, el espíritu rancherocampesino o los fuertes lazos de parentesco- fluyen, 
se actualizan y sirven como características propicias para diferenciarse de otros grupos considerados ajenos, como los jornaleros chiapanecos, en su mayoría jóvenes de entre 15 y 30 años. Con ello se da paso a la formación de un grupo étnico al mero estilo de Barth, para quien estos son categorías de adscripción e identificación utilizadas por los actores mismos y, por tanto, con la característica de organizar la interacción de individuos (Barth, 1976). En ese sentido, la identidad alteña es la que media y configura las relaciones sociales y laborales con los jornaleros indígenas.

Antes, con la experiencia migratoria internacional hacia Estados Unidos, se trataba de un "otro" difuso. Ciertamente se sabía y se tenía el referente espacial o incluso experiencial de ese "otro", aun cuando la generalidad de la sociedad arandense no lo conociese a cabalidad — por no haber migrado- . Aun así, según nos comenta Taylor, se podían observar ciertos patrones de la influencia norteamericana en la vida social de los arandenses, situación que no era más que la expresión de un "otro" cuyo estilo de vida y cuya sociedad representaban en cierto sentido una aspiración que, incluso ahora, se materializa en una imitación de los estilos norteamericanos. Hablamos por ejemplo de que en general el joven arandense tiende a emular ciertos comportamientos extranjeros, y más si ha migrado a Norteamérica o tiene una estrecha conexión familiar con quien ha migrado. Ahí tenemos el regreso de cientos de jóvenes durante las festividades del pueblo, en los meses de enero y septiembre principalmente, cuando salen a relucir los automóviles y camionetas modificadas o acondicionadas al "estilo chicano", incluso las reuniones nocturnas en un punto determinado del pueblo, por parte de quienes manejan estos autos, mostrando todas sus modificaciones, escuchando música en inglés a un volumen estrepitoso, o usando una vestimenta que trata de manifestar una identificación con productos y marcas del vecino país - jeans o bermudas holgadasflojas, playeras, gorras de béisbol, tenis e incluso paliacates en la frente-.
En la actualidad, ese "otro" ha llegado a tierras arandenses, está ahí, se ha corporalizado, mas no en la forma esperada, siendo por tanto una especie de aberración a los prototipos anhelados por los alteños. Es un "otro" que ciertamente rememora parte de un pasado nacional pero que, no obstante, no tiene cabida en la historia enseñada en la región. Por tanto, la migración indígena propicia que los alteños de Jalisco reafirmen su identidad colectiva para crear una especie de barrera frente a lo que se presenta como ajeno:

[...] Los chiapanecos utilizan los usos y costumbres a conveniencia. Cuando les conviene son más prudentes, civilizados, hablan español o incluso visten normal. Y cuando no, también son cerrados, en defensa de preservar sus usos se cierran... Son cabrones y guandajos, salvo sus excepciones, nada más se les ocurre orinar y lo hacen donde sea, golpean a sus mujeres, se ponen violentos al embriagarse, cosas que les son permitidas en sus comunidades [en Chiapas], pero aquí no van [en Arandas]... (entrevista a José López, 2010, Arandas). ${ }^{6}$

[...]Es cierto que en los últimos años, con las generaciones más recientes, ha habido una pérdida del nivel educativo de los arandenses. Ya no se les enseñan y por tanto no se conocen ni se viven los valores arandenses; así como también hay pérdida de identidad por la influencia de gente de otros lugares... (entrevista a Daniel Fonseca, 2009,Arandas).

Presentar al colectivo arandense o alteño como un grupo étnico puede parecer aventurado, sobre todo si partimos del supuesto de que la etnicidad tiene que ver exclusivamente con grupos minoritarios o con herencia indígena, cosa que en nuestro país se ha conjugado. Pero si entendemos por etnicidad aquella dimensión de la vida social que hace que todos los miembros de un colectivo sean vistos como pertenecientes al mismo a través de una etiqueta, el caso de los alteños 
puede ser sin duda uno de ellos. La etnicidad como tal genera una "otredad" por medio de una etiqueta social que se manifiesta mediante una serie de rasgos, sean culturales o raciales. Por tanto, debemos reconocer que la etnicidad siempre tiene su origen en fuerzas históricas específicas-estructurales y culturales. No es un rasgo ontológico de la organización humana (Comaroff, 1992), es una cuestión de clasificación; la separación y reunión de la población en una serie de categorías definidas en términos de "nosotros" y "ellos" (Epstein, 1978). Como vemos a continuación:

[...] Hay mucha diferencia entre un jornalero de Chiapas y uno de Arandas. Los de Chiapas son más cerrados, tienes que decirles como 10 veces las cosas para que hagan las cosas como uno quiere y no como ellos la entienden... 'Son como unos burritos de trabajo` Nunca dejaron de hablar su dialecto, aunque les insistí que hablaran bien... (entrevista a Ramiro Jiménez, 2009, Arandas).

Ahora bien, es importante reconocer que la etnicidad se mezcla y, por tanto, no es ajena a otras dimensiones de la vida social tales como el género y la clase. Habría que matizar entonces que los ejes de la división étnica coinciden a menudo con nuevas dimensiones de clase. El problema sigue siendo por qué, si el interés sirve como el principal determinante de la conducta, la afiliación étnica habría de tener prioridad sobre los vínculos de clase, como sucede con frecuencia (Epstein, 1978).

Es menester reconocer también que la etnicidad implica tres elementos interrelacionados, los cuales actúan no siempre al mismo nivel o graduación, e incluso ni siquiera en conjunto: la identidad, la cultura y el poder. Al referirnos a la identidad traemos a colación a colectivos que se identifican y son identificados. La cultura es otro elemento que se utiliza para marcar a una colectividad generando una escala para la etiquetación y la valoración social o, dicho según Barth, no es sino la forma de describir la conducta humana (1976). El poder marca la pauta para entender las relaciones de desigualdad y dominación, pues todas las dimensiones de la vida social están ordenadas jerárquicamente. Para los fines del presente escrito, abordaremos primordialmente el eje de la identidad, aunque no por ello cultura y poder se dejan de lado. Considero que, con base en la argumentación, se pueden ir rastreando los contenidos de dichos ejes, aunque se encuentren en un constante" ir y venir" en los procesos en cuestión:

Esos pinches chiapanecos vienen y abaratan el jale porque ellos cobran barato...o no es que cobren barato sino que a veces trabajan más por lo que les pagan y nos joden a todos...y luego ahora hasta las morras nos andan bajando, ya se oye que unas viejas de Betania se casaron con unos chiapanecos bien prietos, que porque son bien trabajadores....al rato ni trabajo ni mujeres va a haber para nosotros...me dijeron que ya hasta tienen un equipo de futbol en la liga municipal de puros patarrajadas... dice Miguel Rodríguez (Ríos, 2008).

Para referirnos a la identidad, es preciso reconocer que ésta se crea en las relaciones. En el caso de los alteños podríamos pensar en tres momentos en los que la identidad se ha ido configurando: el primero de ellos, en las relaciones coloniales a través de la formación de una región con claras intenciones de diferenciarse y protegerse de los habitantes originarios de dichas zonas; un segundo momento tiene que ver con la migración internacional de arandenses, cuyo estilo de vida y cosmovisiones se ven confrontados por la experiencia del abandono - temporal o definitivo - del terruño; y un tercer momento es el de la migración interna de jóvenes jornaleros indígenas a la región alteña de Jalisco.

Barth (1976) nos ha enseñado que la identidad se da en el proceso de la interacción, de tal suerte que incluso la cultura que define a los grupos es generada por la misma interacción. No es algo estático e inmutable, sino todo lo contrario: cambia. No obstante, la identidad 
tiende a mantenerse; por tanto, crear identidad es crear frontera. De ahí la importancia de los límites étnicos, que son sociales $y$, aunque pueden contar con su concomitante territorial, canalizan la vida social ocasionando una organización a menudo muy compleja de relaciones sociales y de conducta (Barth, 1976). De manera concreta, dichos límites sociales los podemos constatar a través de una comparación entre pares. Es decir, al hablar de los alteños y su contraparte chiapaneca, podemos ver que ambos colectivos se encuentran mediados por condiciones de clase, raza o género, entre otros, que posicionan a unos y otros en una sociedad segmentada. Mientras, por ejemplo, un joven alteño asiste a la preparatoria, sale por las tardes a divertirse, a hacer deporte o a participar en algún grupo de interés, el joven chiapaneco labora en los campos de agave, tomate o rastrojo, siendo incluso su migración una especie de rito de paso hacia una edad adulta, no en términos numéricos, pero sí en términos culturales, lo cual le posibilita hacerse cargo de una familia. En el ámbito relacional en Arandas, cabe mencionar que las relaciones sociales prácticamente son nulas entre los arandenses y los chiapanecos, de tal manera que las relaciones son casi exclusivamente laborales.

En ese sentido, la identidad representa el proceso por el que la persona trata de integrar sus diferentes estatus y roles, así como sus diversas experiencias, en una imagen coherente de sí misma (Epstein, 1978). No sólo se crea hacia afuera por contacto con otros, sino también a nivel interno; de ahí que la identidad no se entiende sin la parte emocional, pues se mueve dentro de lo afectivo, dejando de ser exclusivamente consciente, racional o cognoscitiva para ser también inconsciente. De este modo, el apego a los parientes, la participación en redes sociales y familiares, así como la identificación en el espacio de residencia y la participación en círculos estrechos de amigos, no sólo sirven para definir los límites del grupo con los que se identifica uno, sino que también proporcionan un mecanismo importante para conservar esos límites (Epstein, 1978).
Hay que reconocer, por tanto, que el punto de quiebre de la identidad étnica es el origen, un origen que se manifiesta a través de un mito o narrativa fundante sobre el que se engarzan las vivencias cotidianas de quienes lo reconocen como suyo. Pertinente es aclarar que tal mito puede ser verdadero o no; lo importante es que sea funcional a las prácticas del colectivo, en el sentido de dotar al mismo justamente de una identidad.

Parece ser entonces que la identidad alteña de antes era una identidad regional y estaba bien demarcada por condiciones geográficas, históricas y, por supuesto, sociales, sólo que su peculiaridad era la de servir simplemente como referente de ubicación. Ahora esa identidad se ha construido a través de las relaciones entre los sujetos concretos que le dan forma —alteños e indígenas migrantes - como una identidad étnica en el sentido de servir como pretexto diferenciador que identifica y da primacía a un grupo en cuestión mientras que rechaza al otro. Cuando la etnicidad se convierte en la base de la clasificación social y las relaciones de estatus, produce el inefable fenómeno de determinar la importancia de individuos y grupos (Comaroff, 1992). Desde tal panorámica, en el caso alteño se suscita la alineación a un discurso nacional según el cual todos gozamos en teoría de supuesta igualdad, mientras que, en la práctica, ese "otro" es oficialmente inferior. En ese sentido, la otredad se vuelve una invención en la imagen opuesta del uno social, no en una adscripción empírica de una población determinada (Comaroff, 1992). Por tanto, el aparato estatal juega un papel como depositario de la coerción, enmarcada específicamente en una estrategia de inscripción cultural que conecta los significados hegemónicos con la experiencia y la visión de los actores (Alonso, 1994) y, como tal, se nutre de preceptos liberales clásicos - puestos en cuestión en nuestro tiempo, sobre todo por multiculturalistas, pluralistas e interculturalistas - que establecen una supuesta igualdad como ciudadanos, situación que repercute, tal como hemos podido constatar con el pasar de los años, en las diferencias, las minorías, la 
representación y la autonomía. Se trata, por tanto, de una "igualdad moral entre todas las personas socialmente desiguales" (Alonso, 1994).

Alonso insiste en que la inscripción cultural de esta idea del Estado ha sido asegurada en parte mediante la espacialización del tiempo, la reificación de las identidades y la organización simbólica y material del espacio social. La noción común de que el Estado es el representante de la voluntad pública, árbitro neutral por encima de los conflictos e intereses de la sociedad, es efecto de una topografía de binarios jerarquizados cuyos términos están construidos como espacios autónomos. Esta topografía encubre las operaciones de las relaciones de poder y las formas de disciplina de la vida cotidiana (Alonso, 1994). Tal explicación nos ayuda a entender que los pueblos indígenas han sido considerados, y efectivamente relegados, en tiempo y espacio, es decir, la noción de lo indígena ha pasado a ser referente de retraso y de obstáculo, por ejemplo, para el progreso y, por tanto, ser depositario de la condición indígena es muestra de ignorancia o falta de empuje para ceñirse a la existencia de una supuesta identidad nacional que, al permanecer invisible, es exitosamente inscrita como la norma. Por último, y no por ello menos importante, la matriz espacial materializada en el ejercicio del sistema estatal moldea la forma en que la sociedad se imagina la identidad social y el territorio. De ahí también la constante vinculación de lo indígena con lo precario, las serranías, lo alejado o lo incivilizado, con lo que, además, se espacializa en una jerarquía de lo civilizado (Alonso, 1994). Esta disputa se hace evidente no sólo en la confrontación del alteño jalisciense con su contraparte chiapaneca, sino al interior de la población alteña, personificada en la figura del ranchero-campesino versus los habitantes de las cabeceras municipales.

El discurso y las prácticas en torno a la otredad adquieren fuerza a través de una conciencia colectiva que marca la pauta para comprender parte del proceso identitario alteño en el sentido de que tal conciencia supone la formulación de identidades colectivas y su representación simbólica en marcadores de contraste entre grupos sociales (Comaroff, 1992), los cuales, para el caso que nos ocupa, tienen que ver con la recurrencia al pasado histórico de formación de la región, en donde además se reifican ciertos atributos físicos - tez blanca, color de ojos, estatura - y valores morales y religiosos — piedad, devoción, fe, honradez, franqueza-, que a su vez se actualizan en prácticas cotidianas de trato hacia los indígenas, bien de rechazo o de benevolencia fincada en la idea de este grupo humano como ávido de compasión, apoyo o empuje para lograr salir adelante.

Sugiero entonces la necesidad de considerar la estrecha relación entre el concepto de conciencia colectiva de los hermanos Comaroff y el de cultura íntima de Epstein, entendido este último como las expresiones más sutiles del comportamiento étnico que se revelan en la vida diaria del hogar, en la compañía de los amigos o en reuniones étnicas. Es decir, nos referimos al componente afectivo de la etnicidad que intenta buscar y definir los valores y actitudes manifestados en las situaciones íntimas (Epstein, 1978). A donde quiero llegar es a afirmar que la etnicidad ciertamente se vive en un plano social y colectivo de identificación o de adscripción, pero no podemos dejar de lado que dicha experiencia es vivida de manera personal e íntima, con influencia no sólo en el nivel consciente, sino también en su contraparte inconsciente, lo que se refleja en hábitos naturalizados.

Los contenidos de la identidad alteña antes mencionados han sufrido transformaciones a lo largo de su historia; sin embargo, parece ser que se están esencializando y buscando un proceso de purificación a raíz de la presencia de los jornaleros indígenas chiapanecos. En ese sentido, se rescata la presencia indígena criolliza-blanquiza en las relaciones sociales, es decir, la pureza del elemento blanco por parte de la sociedad receptora, más que del elemento mestizo.

Cuando en los párrafos introductorios refería la analogía de la destilación, la usaba para indicar justamente este proceso de "separación" y "purificación" 
a través de los límites étnicos donde se da la creación, la recreación o más bien la actualización de la identidad alteña en un contexto relativamente novedoso. Frente al indígena migrante y sus prácticas culturales y sociales, resalta la necesidad de identificarse de una determinada manera: honrados, francos, trabajadores-emprendedores, devotos y blancos, marcando justamente el límite ante una manera "otra" de concebirse que quizá pueda alterar el orden social y cultural establecido. En esta perspectiva, la etnicidad asume una preeminencia vivencial y práctica para aquellos que la comparten, tal como afirman los hermanos Comaroff (1992), lo cual además implica la afirmación complementaria del propio colectivo y la negación del otro, pudiendo incluso poner en tela de juicio la humanidad compartida. Piénsese, por ejemplo, en el fenómeno de la alcoholización juvenil: en el caso de los alteños, concretamente de los arandenses, ingerir bebidas embriagantes o propiamente tequila parece ser símbolo de valentía, independencia, astucia, sagacidad o destreza, todas expresiones que sirven para halagar y resaltar la figura del joven que ingiere. De hecho, en muchos casos alcoholizarse hasta ya no saber de sí, más que motivo de preocupación es motivo de risa y de una historia épica. Sin embargo, si el que se alcoholiza es el joven chiapaneco, es motivo de escándalo y, por supuesto, de preocupación, pero no por la persona que ingiere, sino por el supuesto daño que puede causar, dado que los chiapanecos son considerados como incivilizados aun cuando el acto que realicen sea el mismo:

[...] son bien pinches borrachos los chiapanecos, es más, párate en la puerta (del negocio) y ahorita vas a ver que pasan unos cuantos bien pasados (borrachos), todos los días pasan por la tarde después de la chamba... (entrevista a Jesús Velázquez, 2010, Arandas).

[...] a mis padres no les parecía conveniente (acercarse y charlar con ellos a solas) dado la fama que tienen los que vienen de Chiapas de ser bebedores, así que con la finalidad de protegerme me sugirieron que empezara terminándose las fiestas... (entrevista a Susana López, 2010, Arandas).

[...] se les ha caracterizado por ser borrachos y violentos, pero violencia con cuchillo... (entrevista a Daniel Fonseca, 2009, Arandas).

El surgimiento de distinciones étnicas en una zona dada como Los Altos de Jalisco es posible, por tanto, gracias a la categorización de los sectores de la población en categorías de status exclusivas e imperantes y a la aceptación del principio de que las normas aplicadas a una categoría pueden ser diferentes de las aplicadas a otra (Barth, 1976), siendo las de más prestigio y estima social las del grupo que se encuentra en condiciones más favorables. No debemos perder de vista el hecho complementario de que la identidad que se le imputa a un grupo social desde el exterior puede ser muy diferente de como se experimenta esa misma identidad subjetivamente (Comaroff, 1992). Por otrolado, tampoco debemos olvidar que somos lo que somos en virtud de algún atributo o propiedad común que vemos y compartimos en oposición a aquellos que percibimos que no la poseen (Epstein, 1978).

De tales apreciaciones sucede que un colectivo diferente a lo que se supone común quede localizado en el último escalafón de la estima social, garantizando con ello una desigualdad generada por relaciones étnicas, cuya máxima expresión será el racismo. Se desprende entonces que lo étnico se configura como principio rector de las relaciones sociales y laborales, generando dos colectivos diferenciados: el chiapaneco y su contraparte alteña; viéndose el primero de ellos más perjudicado por la exclusión y la desigualdad, ya que se busca la figura del indígena para marcar la superioridad del alteño contra un sujeto al que, por ejemplo, será permisible pagarle menos. Además, por ser indígena ni siquiera se le presentarán posibilidades para integrarse a un grupo de interés - cultural, deportivo, artísticoLa etiqueta indígena servirá, por tanto, para categorizar 
la vida social que en otros casos puede generar o no comunidad, pero genera una condición, tal como han puesto de manifiesto los Comaroff (1992), al mencionar los orígenes de la etnicidad en la incorporación asimétrica de grupos de estructura diferente en una sola economía política: "los chiapanecos hacen que el costo de producción sea más barato. Rinden más, porque allá (en Chiapas) trabajan de sol a sol, son más productivos" (entrevista a Daniel Fonseca, 2009, Arandas).

Laetnicidad seconvierteenfactordela maduración de un orden capitalista colonial y poscolonial caracterizado por marcadas asimetrías. Siguió proporcionando una base cultural y organizacional para una división del trabajo muy estratificada, y racionalizó la posibilidad de ascenso social y su rasgo distintivo — carácter-ethos de éxito (Comaroff, 1992)—, posibilitando además la desigual distribución de poder material, político y social en virtud de la pertenencia a un grupo.

Para los fines del presente escrito es pertinente reconocer que dentro de México, sin lugar a dudas, quienes han padecido negativamente los estragos de la etnicidad son los pueblos indígenas que han sido incorporados a un sistema de clasificación heredado del colonialismo en el que se fusiona lo racial y lo étnico, ubicándolos debajo de los mestizos y "blancos españoles", quienes supuestamente han preservado su herencia española por más de 500 años. Dichas prácticas son, por tanto, una expresión de lo que afirma Quijano: la prevalencia de un racismo histórico-estructural implantado en el continente americano durante la Colonia que impuso una serie de condicionantes a la población indígena, causas de la posterior exclusión y explotación en su propia tierra (Quijano, 2000). Aunque tales categorías son ciertamente históricas y culturalmente construidas y no biológicas, continúan operando con fuerza política y social en varias partes de México, tal es el caso de los jornaleros indígenas chiapanecos en Los Altos de Jalisco (Stephen, 2007).

Esta fusión entre lo étnico y lo racial es de suma importancia para el caso de estudio debido a que da la pauta, según parece, para entender esto que llamo "racismo contemporáneo", ello porque primordialmente ya no se trata del racismo clásico que sustenta sus mecanismos de exclusión en un determinismo biológico. Ahora el determinismo pasa a la esfera de lo cultural y étnico como factor definitivo en la lógica de las relaciones sociales. Se trata, además, de un racismo en el que un grupo de mestizos, dígase alteños de Jalisco, recrean y dan forma a nuevas relaciones de sumisión, subordinación y discriminación enmarcadas en un contexto de reconversión productiva en el que, además, un producto global como el tequila se sustenta en este tipo de relaciones precarias. Nos topamos así con una práctica racista enmarcada en el espacio laboral de una agroindustria enclavada a su vez en el mercado global que hace, en general, de la constatación de las diferencias fenotípicas culturales, y de la desprotección social, laboral y estatal, sus herramientas más socorridas para discriminar, segregar, excluir y explotar al migrante.

Muestra de ello es que la identificación con el estado natal y la apariencia fenotípica de los jornaleros migrantes se conjugan para dar lugar a una clasificación (Stephen, 2007). Esta aseveración es importante debido a que uno de los "marcadores" de los que se sirve la población alteña en Jalisco para diferenciarse de los "otros" es, como se dijo, su tez de tonalidad clara. De esta manera, una de las distinciones esenciales gira en torno a quién se asume como blanco y quién es identificado como "moreno" o "prieto", lo que además se conjuga con el lugar de procedencia y su consiguiente generalización. Me explico: con los acercamientos que hasta el momento se han tenido, tanto con la población alteña de Jalisco como con la población de jornaleros migrantes, he podido constatar que no todos los jornaleros provienen ni del sur, ni específicamente de Chiapas, sin embargo, hay que decir que para el común de la población alteña toda persona con ciertos rasgos - morenos, de estatura baja, hablantes de otra lengua - pasan a ser "chiapanecos", constatando así que la jerarquía racial de México está espacialmente 
articulada a través de la geografía y etiquetamiento de localidades (Stephen, 2007) y, aún más, ese apelativo tampoco distingue edades, pues a fin de cuentas es gente que "sólo está ahí para trabajar".

El término chiapaneco pasa de ser un referente del lugar de procedencia a una etiqueta de identificación, y por tanto de separación, que expresa la cotidiana discriminación hacia la población migrante y que además se nutre del hecho de que la mayoría de la población migrante que llegó a laborar en Los Altos de Jalisco se identifica a sí misma como población indígena. En ese sentido, las distinciones étnicas son los marcadores primarios de la diferencia en México, particularmente en términos del grado en el que la gente adopta una identidad indígena construida sobre un lugar, un lenguaje y una autonomía étnica (Stephen, 2007).

Estas etiquetas raciales conceptualizadas en la expresión 'chiapaneco' no sólo denotan un imaginario o una ideología de dominación — de exclusión por un lado y de sumisión, subordinación y marginación por otro-, sino que, por supuesto, se materializan a través de la espacialización de las diferencias (Alonso, 1994). Expresión de ello es la identificación de lugares y actividades como "propios" de los jornaleros indígenas - los lugares donde están avecindados, sus lugares de trabajo y la plaza de armas municipalmanifestando con eso una supuesta inferioridad de indígenas migrantes respecto a los trabajadores no indígenas, lo que puntualiza la dicotomía indígena/no indígena (Stephen, 2007). Hay que reconocer también que no todas las etiquetas son impuestas o contienen una carga negativa; ciertamente existe por lo menos una en sentido positivo: la apreciación laboral. Sin embargo, dicha apreciación, lamentablemente, termina por ser un parámetro del que se sirven los empleadores para lograr la explotación. De esta manera, por un lado hay una apreciación laboral, pero en lo social hay discriminación, exclusión y marginación.

\section{Consideraciones finales}

Con la llegada de los jornaleros chiapanecos a las tierras alteñas de Jalisco se ha suscitado un fenómeno de destilación de identidades en el que, por un lado, han aflorado los elementos constitutivos y delimitadores de lo alteño, de lo cual no han sido excepción los jóvenes arandenses, mientras que, por otro lado, se han atribuido a, e identificado en "los otros", características que sirven para segregarlos, marginarlos y explotarlos. Por tal motivo, el análisis de la etnicidad, a partir de la narrativa en torno a la formación de la región alteña, ha sido primordial para mostrar los discursos y prácticas en los que se sustentan las desigualdades, las cuales, como se vio, se viven de manera íntima y por tanto dan lugar a comportamientos naturalizados que coexisten de manera inconsciente, pero que se materializan en el cotidiano interactuar.

El establecimiento de relaciones de desigualdad hacia el grupo migrante obedece ciertamente a causas histórico-estructurales; sin embargo, dichos factores se han conjugado con una actualizada imagen identitaria del alteño que, en el fondo, sigue resguardando aquello que por décadas fue distintivo de la región y que ahora, como hemos apreciado, es distintivo del grupo: composición social, política, religiosa o económica. El hecho es que la identidad étnica alteña se ha visto confrontada no sólo por la emigración de sus gentes, sino por la inmigración de jóvenes jornaleros justamente a un territorio concebido como auténticamente propio, motivo por el cual ha emergido un proceso de destilación en el que, de manera consciente o no, se busca aquello considerado propio del grupo, digno de rescatarse o, incluso, de impedir que se manche.

\section{Notas}

${ }^{1}$ La destilación en la industria tequilera es un proceso consistente en el calentamiento mediante aplicación de vapor a presión al fermento del agave, con la 
finalidad de separar productos de riqueza alcohólica - tequila - y vinazas —estas últimas constituyen un producto de desecho-. Por tanto, el objetivo principal de la destilación es separar una mezcla de varios componentes aprovechando sus distintas volatilidades, o bien separar los materiales volátiles de los no volátiles para así obtener el componente más volátil en forma pura. Dicho proceso se lleva a cabo ordinariamente en alambiques de cobre o acero inoxidable. Los alambiques comunes constan de tres partes: la olla o caldera, donde se deposita el mosto para su calentamiento; la columna o capitel, que recoge y conduce los vapores; y el serpentín, en el que se enfrían los vapores y se vuelven líquidos. Los puntos de ebullición de los diferentes compuestos, así como los diversos volúmenes y presiones del alambique, ayudan a la separación de gases, que se condensan en productos de mayor riqueza alcohólica. En la elaboración del tequila son necesarias dos destilaciones; la primera llamada destrozamiento, y la segunda, rectificación. Con la rectificación se incrementa la riqueza alcohólica y se eliminan los productos indeseables, obteniendo así uno de mayor pureza. Al tequila que se recibe del destrozamiento o primera destilación se le llama "tequila ordinario", y el que termina la segunda destilación o rectificación es considerado como "tequila blanco". Además de las vinazas, existen otros subproductos del inicio y final de la destilación conocidos como "cabezas" y "colas", respectivamente (Consejo Regulador del Tequila, 2012)

2 "La extensión geográfica de Los Altos de Jalisco se divide en dos regiones administrativas: Altos Norte y Altos Sur (para los fines del presente trabajo nos referiremos fundamentalmente a "Los Altos de Jalisco" para hacer alusión a la región Altos Sur). Esta última cuenta con una extensión territorial de 6.667 kilómetros cuadrados que representa aproximadamente el cinco por ciento de la superficie del Estado. Las actividades económicas de esta región son la agricultura, ganadería y la industria alimenticia abarcando una vasta extensión de tierras para el cultivo del maíz grano, maíz forrajero y agave (tequilana weber variedad azul), así como para la producción ganadera de ovinos, bovinos, porcinos y aves de corral. Los Altos tienen diversas definiciones en términos de su cobertura territorial. Cada una de estas definiciones responde a una perspectiva de análisis particular. No hay unanimidad respecto de cuáles municipios pertenecen a esta delimitación cultural y geográfica del estado de Jalisco, manejándose cifras entre diecinueve y veintiséis municipios [...] Lo común [...] es que lo alteño gravita en medio de un campo de fuerza formado por las principales ciudades del centro occidente: Guadalajara, Aguascalientes, León, San Luis Potosí..." (Gilabert, 2004: 33).

3 Título en castellano: Arandas, Jalisco: una comunidad campesina.

4 Taylor reconoce que, aunque en su estudio fue seleccionado el municipio de Arandas, en el estado de Jalisco, México, es al mismo tiempo representativo de una región más amplia: Los Altos de Jalisco (Taylor, 1989).

${ }^{5}$ Con la expansión de la agroindustria tequilera y el posterior boom internacional del tequila durante la década de los noventa del siglo pasado, la actividad agrícola dio un vuelco considerable; la sobreproducción del agave y el posterior incremento de fábricas productoras de la tan conocida bebida espirituosa generaron una importante transformación industrial y económica en varios municipios de la región. A raíz de todo este proceso, el mercado laboral sufrió alteraciones de manera que, para cubrir la demanda de mano de obra local y regional, algunos de los empresarios tequileros llevaron a decenas de jornaleros desde el sureste mexicano en 1998. Hernández (2005) da cuenta de cómo incursionaron los primeros jornaleros del sureste a tierras alteñas; a saber: las sequías sucedidas en el norte del país en la década de los noventa aumentaron el valor del forraje y disminuyeron el del ganado criado en aquellas tierras. Esta coyuntura de escasez de agua torrencial al sur de Estados Unidos propició la venta 
de ganado barato y de poco peso, circunstancias que fueron aprovechadas por los ganaderos alteños. El ganado comprado en aquellas latitudes fue trasladado al sureste del país. En aquella zona, y desde hace tres décadas, varios jaliscienses productores de carne engordan su ganadería en pastizales ubicados en predios de su propiedad o arrendados a comunidades indígenas. El ganado se alimenta de follaje durante meses, estando al cuidado de uno o dos peones locales quienes perciben un jornal de 30 pesos diarios. Llegado el tiempo de la venta, los animales se comercializan en México y en los mismos Altos de Jalisco. Un pequeño porcentaje es dejado en la localidad donde igualmente se vende en carnicerías o restaurantes de los mismos propietarios. Un par de ganaderos alteños, oriundos de Atotonilco El Alto, Jalisco, invirtieron en plantaciones de agave que realizaron con mano de obra transportada desde Palenque, Chiapas. Algunos de estos jóvenes chiapanecos pastoreaban el ganado propiedad de estos alteños en fincas ubicadas en los límites con Tabasco (Hernández, 2005: 6). Con el paso del tiempo y el establecimiento de redes de migración, comenzaron a llegar personas provenientes de Ocosingo, San Cristóbal de Las Casas, Las Margaritas, Tuxtla Gutiérrez y Tapachula, así como de otras comunidades aledañas a estos sitios y regiones de Chiapas. Los jornaleros que mayoritariamente migran son una población cuya edad oscila entre los 16 y 30 años; no obstante, existen casos de personas con mayor o menor edad. Con el pasar de los años, familias completas se han establecido en Arandas. Del total del grupo de jornaleros indígenas con el que se ha tenido contacto - 300 aproximadamente, de los cuales las mujeres no llegan a 30-, muy cerca del 50\% es soltero y la otra mitad vive en unión libre; de estos últimos hay que destacar que la mayoría proviene de familias numerosas, en donde la media es de siete a diez miembros. Las familias establecidas en Arandas son alrededor de 20, con un número de integrantes que ronda los seis. Se ocupan mayoritariamente en labores del campo; por tanto, no están disociadas con respecto de las actividades que realizaban en el lugar de origen. En cuanto a las mujeres, destaca el hecho de que también empiezan a tener una presencia considerable, dado que en primera instancia migraban sólo varones. La mayoría de ellas, un 90\%, viajó para acompañar a su pareja, algunas laboran a la par de él como empleadas domésticas, otras, quizá la gran mayoría de ese total, se reducen a la esfera de lo privado como amas de casa. El otro 10\% llegó por medio de algún familiar. Este grupo, al igual que el anterior, se desempeña mayoritariamente en el servicio doméstico. Resulta interesante constatar que existen mujeres cuya pareja las llevó a Los Altos de Jalisco, pero en fechas posteriores él regresó a Chiapas a trabajar dada la falta de empleo en un momento determinado.

${ }^{6}$ Los nombres de los entrevistados han sido cambiados a fin de respetar su privacidad.

\section{Bibliografía}

Alonso, Ana María (1994), "Políticas de espacio, tiempo y sustancia: formación del estado, nacionalismo y etnicidad", en Camus, Manuela (2006), Las ideas detrás de la etnicidad. Una selección de textos para el debate, Antigua Guatemala: Cirma, pp. 96-114.

Barth, Frederick (1976), Los grupos étnicos y sus fronteras, México: FCE.

Comaroff John and Jean (1992), Theory, ethnography, historiography, San Francisco, Oxford: Westview Press, Boulder.

Consejo Regulador del Tequila (2012), El Tequila, elaboración. 〈http://www.crt.org.mx/> [27 de julio de 2012].

Epstein, E. P. (1978), Ethos and identity. Three Studies in ethnicity, Londres: Tavistock Publications.

Fábregas, Andrés (1986), La formación histórica de una región: Los Altos de Jalisco, México: CIESAS.

Fábregas, Andrés y Pedro Tomé Martín (2001), Entre parientes. Estudios de caso en México y España, México: El Colegio de Jalisco. 
Fábregas, Andrés y Pedro Tomé Martín (2002), Regiones y fronteras. Una perspectiva antropológica, México: El Colegio de Jalisco.

Gilabert Juárez, César y Margarita Camarena Luhrs (2004), El alteño global. Trayectorias evolutivas de Los Altos de Jalisco: evolución política y sociocultural en la era de la sociedad global, México: Universidad de Guadalajara y El Colegio de Jalisco.

Hernández López, José de Jesús (2005) “Encontrar el norte en Los Altos de Jalisco. La migración de jornaleros chiapanecos a los campos agaveros", en V Congreso de la Asociación Mexicana de Estudios Rurales (AMER), Balance y perspectivas del campo mexicano; a una década del TLCAN y del movimiento zapatista. Oaxaca.

López Cortés, Eliseo (1999), Último cielo en la cruz, México: Universidad de Guadalajara y el Colegio de Jalisco.
Quijano, Aníbal (2000), "Colonialidad del poder, eurocentrismo y América Latina”, en Lander, Edgardo (comp.) (2000), La colonialidad del saber: eurocentrismo y ciencias sociales. Perspectivas latinoamericanas, Argentina: CLACSO.

Ríos, Julio Alejandro (2008), "La otra migración”, en Proceso, Jalisco, marzo, núm. 1686, México, p. 16.

Stephen, Lynn (2007), Transborder lives. Indigenous Oaxacans in Mexico, California and Oregon, Durham y Londres: Duke University Press.

Taylor, Paul. S. (1989), “A Spanish-Mexican Peasant Community. Arandas in Jalisco, México”, en Durand, Jorge (comp.), Migración México-Estados Unidos. Años Veinte, México: Conaculta.

Yáñez, Agustín (1978), Las tierras flacas, México: Editorial Arte y Literatura. 